\title{
PALEOPATOLOGÍA DE LA MANO
}

\section{Domingo Campillo}

Jefe del "Laboratori de Paleopatologia i Paleoantropologia del Museu d'Arqueologia de Catalunya" y Prof. de Historia de la Medicina en la "Universitat Autònoma de Barcelona". Barcelona (España)

\section{RESUMEN}

La mano, órgano esencial de la especie humana, seguramente ha sufrido afecciones patológicas iguales o semejantes a las actuales; sin embargo, los paleopatólogos no las hemos constatado hasta períodos muy recientes, seguramente debido a los procesos tafonómicos. En el presente trabajo aportamos nuestra experiencia y revisamos someramente los casos publicados por otros autores que hemos podido consultar, incluyendo las prácticas punitivas y rituales a que los humanos se han visto sometidos.

\section{SUMMARY}

The hand, essential organ of the human species, surely has suffered patological affections equal or smimilar to the present day ones, nevertheless, the paleopathologists have not verified them until very recent times, certainly due to the taphonomic processes. On the present study we furnish our experience and, check superficially, the cases published by other authors that we have been able to consult, including the punitive and ritual prectices that the human have been subjugated.

\section{INTRODUCCIÓN}

El hombre como primate, tiene una serie de características comunes a su orden zoológico y otras particulares propias del género y especie a que pertenece. No comentaremos todas las características comunes a su orden limitándonos a aquéllas que guardan relación con las manos. En los primates se conservan una serie de caracteres arcaicos que se combinan con otros muy evolucionados: entre los primeros están la pentadactilia, ya presente en muchos reptiles del secundario, y la persistencia de las clavículas, y entre los segundos, el gran desarrollo del encéfalo, la visión binocular cromática y la oposición del primer dedo, por lo menos en las extremidades anteriores o superiores. En el caso concreto del hombre, es de destacar la amplia representación cortico-cerebral motora para la mano en la circunvolución frontal ascendente y otro tanto ocurre, en la parietal ascendente, con el área reservada a la sensibilidad táctil. En el hombre la oposición del pulgar alcanza su grado máximo, siendo el quinto dedo en menor grado también oponible. La sensibilidad cutánea de la mano, sobre todo a nivel del pulpejo de los dedos, alcanza un nivel muy alto, como lo de- 
muestra el elevado número de líneas que constituyen los dermatoglifos humanos. Como en la mayoría de los primates, la presencia de uñas planas en lugar de las garras es otra ventaja. También hemos de resaltar que el pie en el hombre es un órgano muy evolucionado para la bipedia, que difiere mucho de la estructura de la mano.

Los paleoantropólogos han discutido durante mucho tiempo la importancia evolutiva de la mano en relación con el cerebro, según se ha ido valorando su primacía en consonancia con el registro fósil, en el que se basa el árbol filogenético de la especie humana. La opinión actual más generalizada es que el primer logro fue conseguir la oposición del dedo pulgar y en los primates prehumanos alcanzar la bipedia, con lo que las extremidades anteriores dejaban su actividad locomotriz y se especializaban en la prensil, siendo posterior el aumento volumétrico del cerebro, al que el hombre debe su primacía en la escala zoológica del planeta. Estos hechos se ven confirmados por el registro fósil, con las huellas de pisadas de australopitecinos en Laetoli, por la estructura de la pelvis y del astrágalo en el Australopithecus afarensis $3 ' 5$ millones de años (m.a.), constatándose que el aumento volumétrico cerebral es posterior a la bipedia. Se ha dicho, que sin la bipedia y la liberación de la mano, ningún primate habría llegado a hombre.

La importancia funcional de la mano, en dependencia con unas complejas estructuras anatómicas, controladas por el sistema nervioso hacen que su afectación patológica pueda depender de lesiones de localización muy variada, pero en paleopatología la discriminación etiológica resulta muy compleja, aunque se han podido constatar lesiones de la mano atribuibles a procesos locales, a enfermedades sistematizadas, a lesiones neurológicas y a actos rituales o punitivos.

En reptiles con pentadactilia en sus extremidades, que vivieron en las Eras secundaria y terciaria, se han constatado lesiones patológicas a nivel de sus "manos", presumiblemente traumáticas, infecciosas o reumatoideas, pero no nos adentraremos en el campo de la zoopaleopatología y sólo nos refereriremos a los homínidos que precedieron al Homo sapiens sapiens, que será nuestro objetivo principal.

Por sus características, los estudios paleopatológicos no deben limitarse al período histórico, denominado de forma un tanto arbitraria prehistoria, por lo que no nos limitaremos a él adentrándonos incluso en la Edad Media, sin entrar en competencia con los historiadores, considerando nuestra aportación como complementaria.

\section{LOS PRIMEROS VESTIGIOS PATOLÓGICOS EN LOS HOMBRES FÓSILES}

En el Paleolítico inferior, período que abarca desde la aparición de los primeros homínidos seguramente hace más de 4,5 m.a., los restos esqueléticos resultan muy fragmentarios y escasos. El Australopithecus en sus formas grácil y robusta, considerado pre-hombre y el Homo habilis que vivieron hace más de 2,5 m.a., en que el más 
antiguo y mejor conservado la Australopithecus afarensis, de forma coloquial denominada "Lucy", pues su antigüedad se evalúa en unos 3,5 m.a. Los primeros hombres verdaderos constituyen el grupo denominado Homo erectus que incluye a los pre-neanderthalensis europeos, cuya antigüedad seguramente sobrepasa 1 m.a. y que seguramente se extinguen ya entrado el Paleolítico medio, que comienza hace 120.000 años. De todos los homínidos fósiles casi no se conservan huesos de sus partes acras y no se han detectado alteraciones patológicas en los pocos que pertenecientes a las manos se conservan.

Todos estos grupos fueron recolectores, y el Australopithecus gracilis y el Homo habilis también carroñeros, y seguramente cazadores menores, empleando instrumentos de madera, piedra y hueso, que aunque debieron ocasionar lesiones en sus manos, no tenemos evidencia de las mismas. Tampoco tenemos ninguna evidencia de lesiones o patologías de las manos, en el Homo erectus que practicó la caza mayor en la Península Ibérica, pues hubo grupos que cazaron el mamut hace 400.000 años, como se pudo constatar en Torralba y Ambrona (Soria), en donde la excavación arqueológica dirigida por HowELL (1971) descubrió en 1961 los vestigios de una importante cacería de aquellos proboscídeos.

Las primeras evidencias patológicas de las manos las tenemos en un Homo sapiens neanderthalensis, variedad de Homo sapiens que vivió en Eurasia y Africa durante el Paleolítico medio (120.000-40.000 años). Se conservan las del individuo de La-Chapelle-Aux-Saints (Francia) que presenta alteraciones osteoartríticas en la columna vertebral y manos (VALLOIS, 1959 y STEINBOCK, 1973), mientras que las de los individuos femeninos de La Ferrassie (Francia) y de Tabum I (Israel), no muestran alteraciones patológicas (PIVETEAU, 1957).

Las distintas patologías que afectan a las manos comienzan a encontrarse con la aparicion del Homo sapiens sapiens, más conocido como Hombre de Cromañón, que habito en el Paleolítico superior y tampoco hay constancia de este tipo de lesiones, si exceptuamos la interpretación de las pinturas rupestres con representaciones de manos, sugerentes de posibles amputaciones digitales que comentaremos en el último apartado.

Probablemente la lesión más antigua de la mano en el Homo sapiens sapiens sea la publicada por DUDAY (1975), en que comenta la patología de un esqueleto exhumado en 1972 en la cueva preneolítica de Bonifacio (Córcega), cuya antigüedad se remontaría a unos 8.500 años. El esqueleto corresponde a un adulto de sexo femenino de unos 35 años, que presentaba varias fracturas antiguas bien consolidadas en sus extremidades izquierdas: del cúbito con alineación defectuosa en bayoneta asociada a las de los tercero y quinto metacarpianos, con aumento de la incurvación palmar de sus diáfisis, exostosis postraumática del maleolo tibial, asociados a signos artrósicos del calcáneo y del primer dedo del pie. En el momento de la exhumación ya se pudo ver la presencia de una "garra cubital", constatándose en su estudio en el 


\section{DOMINGO CAMPILLO}

laboratorio, la modificación de las facetas articulares y también por radiografía, la existencia de una osteoporosis global de la mano. Por la buena consolidación de las fracturas se supuso que el traumatismo había acaecido mucho tiempo antes de su muerte, siendo la conclusión diagnóstica de un politraumatismo sufrido en vida que afectó a las extremidades izquierdas, lesionándose el nervio cubital, responsable directo de la parálisis de los dedos cuarto y quinto causantes de la garra y, secundariamente a causa de la inmovilidad, se estableció la osteoporosis de la mano.

\section{HALLAZGOS PATOLÓGICOS A PARTIR DEL NEOLÍTICO}

A partir del Neolítico, aparte de algunas lesiones artríticas o artrósicas, poco hay que destacar, siendo ya en la época de la dominación romana y en el medievo y períodos posteriores cuando se pueden constatar algunas patologías a las que nos referiremos a continuación.

\section{Patologías infecciosas}

Osteomielitis. Las enfermedades infecciosas pueden afectar los huesos de las manos, siendo en general la puerta de entrada cutánea o septicémica, aunque las osteomielitis piógenas de las manos son poco frecuentes a nivel de los dedos según destaca STEINBOCK (1973), pues casi no hay casos descritos en paleopatología. En un individuo de la cultura talayótica (siglo V-IV a.C.) exhumado en s'lllot des Porros (Mallorca), tuvimos la oportunidad de examinar unas falanges anquilosadas, caso sospechoso de artritis supurada que habría curado con una flexión moderada (MALGOSA y CAMPILlo, 1991) (figs. 1 y 2). MAFART (1983), en un individuo de los siglos V-VI exhumado en la Abadía de Saint-Victor (Marsella), describió un caso de probable flemón palmar.

Tuberculosis. La afección más frecuente suele ser la denominada espina ventosa, que predomina en los niños. Procedente de la necrópolis visigótica de Clúnia (siglo VII), encontramos una falange que por su aspecto insuflado nos pareció compatible con esa etiología (CAMPILlo, 1986-89) (figs. 3 y 4).

Lepra. Esta enfermedad afecta con frecuencia a las falanges y huesos del metacarpo y del metatarso. La dilatación de los orificios nutricios en estos huesos suele ser característica de la enfermedad y en las fases más avanzadas (BROTHWELL, 1967), las necrosis seguidas de atrofias que se inician por la porción distal de los huesos largos de las manos y pies. En este sentido son importantes los trabajos de MOLLER CHRISTENSEN (1967) que muestran este tipo de lesiones en esqueletos de individuos medievales, procedentes de las necrópolis de los lazaretos daneses. 


\section{Afecciones reumatoideas}

Con este nombre incluimos aquellas afecciones de tipo inflamatorio que afectan al aparato osteoarticular, pues en paleopatología cuando sólo se dispone de los restos óseos, puede ser muy difícil alcanzar un diagnóstico etiológico.

Artritis reumatoide. Por sus peculiares características, de anquilosis con fusión ósea, predilección por determinadas articulaciones y otros datos relevantes, con relativa frecuencia puede diagnosticarse. Nosotros hemos podido estudiar dos casos en individuos del sexo femenino, uno que afecta al carpometacarpo y otro a los metacarpianos y falanges (CAMPILLO, 1983, 1984-85 y 1993). El primero correspondía al período tardo-romano (Quinta de San Rafael, Tarragona) y el segundo, de cronología incierta, procedía del Codolar de Biniatram (Menorca) (figs. 5A y B), probablemente del período pos-talayótico.

Artritis hiperuricémica. De época medieval, atribuidas a hiperuricemias se han encontrado numerosos casos en la Gran Bretaña, que han sido relacionados con la frecuente cocción de la carne con vino en ese período. Por las grandes lesiones esqueléticas, en un individuo de principios de nuestra era, procedente de Trepucó (Menorca), atribuimos a esta etiología sus lesiones artríticas (CAMPILLO, 1984-86) (fig. 6).

\section{Patología neurológica}

Las únicas evidencias de patología neurológica que hemos podido constatar ha sido la presencia de una "garra cubital", que hemos relacionado con lesiones del nervio del mismo nombre. El caso más evidente corresponde a una mujer joven afecta de artritis reumatoide exhumado en la Quinta de San Rafael y que presentaba graves lesiones de fusión ósea a nivel del codo, que justifican plenamente la presencia de las lesiones de la mano, confirmando la frecuente asociación de neuropatías que se mencionan en las descripciones clínicas de esta enfermedad (CAMPILLO, 1993) (figs. 7 y 8).

\section{Anomalias congénitas y hereditarias}

No tenemos constancia en paleopatología de casos que hagan referencia a ectrodactilia, sindactilia, ni polidactilia.

\section{Neoplasias}

Se han constatado algunos casos de osteomas o de exostosis de etiología incierta y MACKE y MACKE-RIBET (1994), en una necrópolis romano-egipcia (siglos I-IV, C.), muestran en una mano infantil momificada, una insuflación de las primera y 


\section{DOMINGO CAMPILLO}

segunda falanges del cuarto dedo, en que la radiografía detecta unas cavidades quísticas sospechosas de un encondroma.

\section{Lesiones traumáticas}

La mayoría de los casos descritos corresponden a fracturas de los dedos o de los metacarpianos, por la frecuente presencia de callos. La mayoría de las veces, la alineación postraumática de las diáfisis es incorrecta. Personalmente hemos podido constatar varios casos (figs. 9 a 11 ).

Nos parece interesante mencionar la presencia de una fractura del escafoides izquierdo, en un individuo de la Edad del Bronce exhumado en el término municipal de Torruella de Montgrí (Girona) en el lugar conocido como La Fonollera (CAMPILLO, 1983, 1984-85 y 1993). Al examinar el hueso fracturado, constatamos una pérdida de substancia ósea de tipo cuneiforme, con recubrimiento por hueso compacto de las superficies del área lesional. Nuestra impresión fue de que se originó una necrosis isquémica por lesión de una rama de la arteria nutricia, originándose una pseudoartrosis (enfermedad de Preisser) (fig. 12). MAFART (1983) describió un caso de necrosis del escafoides en un individuo de la alta Edad Media de Provenza (Francia) y ETXEBERRÍA (1983), otro de época medieval, procedente de la necrópolis de Santa Eulalia (País Vasco, España).

En todas las épocas, generalmente por heridas bélicas o con carácter punitivo, parece ser que la amputación de las manos fue una práctica corriente, aunque sin embargo los casos descritos han sido escasos. Sólo hemos constatado cuatro casos procedentes de la literatura paleopatológica, uno procedente de Sedment (Egipto), perteneciente a la IX dinastia, otro dudoso del siglo $\mathrm{V}$ descrito por DAN MORSE en 1969 y citado por STEINBOCK (1973), el tercero publicado por DASTUGUE procedente del cementerio merovingio de Verson (Calvados, Francia), el cuarto de época medieval descrito por MAYS (1996), probablemente secundaria a una agresión violenta, y nosotros tuvimos la oportunidad de estudiar un quinto caso, con la amputación de ambas manos, procedente de la necrópolis paleocristiana de La Olmeda (Pedrosa de la Vega, Palencia, España) (CAMPILlo et al, 1992) (fig. 13). Excepto en el caso descrito por DAN MORSE, las amputaciones se realizaron por los antebrazos. Todos los casos recopilados de la literatura correspondían a la extremidad derecha, probablemente la lesionada con mayor frecuencia, tanto en los casos punitivos como seguramente también en los casos bélicos, pues la pluma para la escritura y la espada en la lucha, suelen manejarse con la mano derecha. Que la amputación tenga lugar a nivel del antebrazo, parece lógico, tanto en las acciones bélicas, pues la mano empuña el mango de la espada, y en los casos punitivos, resultaba más sencillo cortar por el antebrazo. 
Los textos antiguos (16) como el "Código de Hammurabi" castiga el robo con la amputación de una mano. Los griegos y los romanos en ocasiones castigaban con la amputación de una mano. En Israel la mutilación estaba prohibida, pero según la Biblia (16) se castigaba mano por mano y también en el Corán se recoge este castigo. Entre los visigodos, en el "Fuero Juzgo" (16), se castigaba con la amputación de la mano a los falsificadores y posteriormente en el "Fuero Real" (16), al escribano que falsificaba un documento. En algunos pueblos primitivos hasta hace poco también persistía este castigo e incluso, en algunas culturas que consideran que la mutilación impide los goces de la vida futura, prefieren la condena a muerte antes que cualquier mutilación (16).

Parece ser que entre los romanos, cuando alguien no quería servir en el ejército se amputaba el dedo pulgar, pues sin él no se puede empuñar la espada (16).

Entre los pueblos antiguos, la amputación de una mano fue realizada con frecuencia para el recuento de los cadáveres tras las batallas, como comenta LECA de los antiguos egipcios. No parece que las amputaciones, en especial de las manos, se prodigase entre los prisioneros, que si no eran ajusticiados, con manos resultaban más útiles como esclavos.

Se ha sugerido que en los tiempos prehistóricos, ante la presencia de manos pintadas en algunas cuevas de la cordillera cantábrica en España y en otras pirenaicas del sur de Francia, en las que aparecen manos impresas con supuestas amputaciones digitales se practicaron mutilaciones rituales, similares a las practicadas por algunos pueblos primitivos que llegaron hasta nuestro siglo. Por su importancia y las controvertidas opiniones les dedicamos un espacio particular.

\section{PINTURAS RUPESTRES CON SUPUESTAS AMPUTACIONES DIGITALES}

En Europa todas las cuevas con pinturas murales de manos pertenecen al paleolítico superior y se encuentran en el norte de España y en la vertiente pirenaica francesa. En algunas se han encontrado imágenes sugerentes de la pérdida de algunos dedos, que determinados prehistoriadores han atribuido a amputaciones digitales rituales, otros a procesos patológicos y algunos consideran que son signos, veleidades artísticas o defectos de impresión.

A continuación nos referimos a las distintas patologías que con mayor frecuencia pueden justificar una pérdida o deformación digital y que las resumimos en el cuadro I. 
DOMINGO CAMPILLO

\section{CUADRO I}

PATOLOGÍA INFECCIOSA:

Osteomielitis piógenas $\mathbf{u}$ otras variedades.

Gangrena.

Tuberculosis.

Lepra.

AFECCIONES REUMATOIDEAS:

Artritis reumatoide.

Artritis psoriásica.

Artritis hiperuricémica.

Artritis esclerodérmica.

PATOLOGÍA NEUROLÓGICA:

Garra cubital.

Mano de la hemiplejía.

Mano de "simio".

Mano de "predicador" o siringomiélica.

En tridente (acromegalia).

En Bandera (poliomielitis).

En gancho de los dedos 3 y 4 (Aran-Duchenne).

AGENESIAS:

Ectrodactilia.

ANOMALÍAS CONGÉNITAS:

Polidactilia.

Sindactilia.

Mano en "pinza de cangrejo".

Displasia frontoepifisarial.

Trisomia con cabalgamiento de dedos ${ }^{1}$.

Síndromes de Charlie, de Hanhart y de Pfeiffer ${ }^{1}$.

TRAUMATISMOS:

Accidentales.

Punitivos.

RITUALES MUTILANTES:

Funerarios.

De iniciación.

Distintivo de casta.

Otros rituales.

OTRAS:

Sindrome de Dupuitren.

${ }^{1}$ según GoRLiN et al. 
Abordaremos el problema desde dos vertientes distintas: patológico y ritual.

\section{Causas patológicas}

Nos referiremos a las mencionadas en el cuadro precedente.

Entre las enfermedades infecciosas, solamente la gangrena y la lepra muestran una tendencia franca a las atrofias y pérdidas digitales, ya que las osteomielitis son raras en los huesos de la mano (STEINBOCK, 1973). La "gangrena seca" debemos considerarla como una patología excepcional en los dedos de la mano, mientras que la gaseosa, por el estado general del paciente, no consideramos que fuese muy adecuada para la implantación de su huella en la pared. Solamente la lepra podría justificar estas atrofias y pérdidas digitales en su fase mutilante, pero hay varios factores contrarios a esta hipótesis. 1, la abundancia de mutilaciones en las cuevas en que éstas aparecen como pinturas nos parece excesivo, pues correspondería a una gran endemia en esa población, ya que los casos mutilantes representan una escasa proporción con respecto a las formas cutáneas; 2, según parece, la mutación del Mycobacterium que dio origen a la lepra, sería relativamente reciente, como mucho hace 25.000 años y probablemente 10.000 años o menos (GRMEK, 1983); 3, parece probable según dicho autor que la aparición de la lepra sea posterior a la última migración de poblaciones humanas a América, continente en que también se encuentran improntas de manos en algunas cuevas (MENGHIN, 1964). Resolviendo esta cuestión, personalmente consideramos que estas patologías no justificarían las improntas de manos amputadas en el Paleolítico superior.

Las afecciones reumatoideas, aunque pueden originar importantes deformaciones digitales, no acostumbran a ser mutilantes.

Las afecciones congénitas pueden originar alteraciones por defecto, agenesias, o por exceso, polidactilia. Ni las unas ni las otras son afecciones de gran incidencia y con frecuencia se asocian a otras malformaciones, muchas veces incompatibles con la vida. Hasta el presente, no hemos encontrado en la literatura paleopatológica, casos sospechosos de dichas etiologías. No nos parece que la improntas de las manos con déficits digitales puedan apoyarse en estas anomalias.

La enfermedad de Dupuytren secundaria a una retracción de la aponeurosis palmar origina la flexión digital irreductible en "garra" de uno o varios dedos, y por su morfología, sería una hipótesis aceptable en la interpretación de las improntas de las "manos mutiladas", predomina en el varón, pero su incidencia no es muy elevada y suele aparecer después de los cincuenta años (SIMON, 1976), edad rara vez alcanzada por los hombres del Paleolítico superior.

Las lesiones traumáticas podrían justificar algunos casos, pero su abundancia más bien nos haría pensar en amputaciones rituales, como las estudiadas por SolLAS y que autores posteriores también comentan (WELLS, 1964 y MOODIE, 1923). 


\section{Amputaciones rituales}

En 1906 CARTAILHAC (1096) describió por primera vez las impresiones de manos en la cueva Gargas, situada en la vertiente francesa de los Pirineos. SOLLAS en 1924 realizó un interesante estudio antropológico sobre las mutilaciones digitales, aportando datos de numerosas culturas primitivas, recopilados entre distintos autores y correlacionando los datos con los hallazgos de pinturas rupestres de manos con la presencia de probables amputaciones digitales, complementando su estudio con un trabajo experimental. Según este autor, la primera aportación sobre esta práctica la realizó BURCHELL (1824) entre los bosquimanos de Sudáfrica (fig. 14), constatando en una mujer anciana que se había amputado en varios episodios el quinto dedo de la mano derecha y posteriormente dos dedos de la mano izquierda como sacrificio por la muerte de tres hermanas, amputación ritual que se realizaba con un cuchillo de piedra. Este autor recopila este ritual en numerosos pueblos primitivos de los cuatro continentes, siendo las motivaciones muy variadas, entre las que a título de ejemplo citamos algunas: signo de duelo en el funeral entre algunos grupos de pigmeos (SCHMIDT, 1910); como compensación punitiva, la amputación de tres dedos por haber matado a un hombre entre los indios de Montana; por el fallecimiento del rey en las islas Fiji; algunas madres por la pérdida de un niño entre los pigmeos negritos de Mafulú; en las islas Nicobar por la pérdida del marido; como ritual religioso entre las mujeres de los dravinianos de la India; etc.

Comenta Sollas (1924), que cuando se analizan estas evidencias, se puede observar que esta singular práctica se reproduce entre un gran número de pueblos muy distantes entre sí, separados por largos espacios de tiempo y por la presencia de barreras geográficas. Piensa que la mejor explicación para este ritual, está basada en la gran antigüedad de esta costumbre antes de la separación de las distintas razas.

Las improntas de las manos en las paredes de las cuevas pueden ser en "positivo" o "negativo" (fig. 15), según se logre con la mano impregnada en un colorante o empleando el método de pulverizar el colorante por encima de la mano. Según Sollas, se detectaron por primera vez en la Cueva de El Castillo (Puente Viesgo, Cantabria, España), que fue descubierta en 1901 y estudiadas por BREUIL en 1911, pero en este caso no eran sospechosas de amputaciones; las más espectaculares son las de la cueva de Gargas (Hautes-Pyrénées, Francia) con más de 160 improntas en color rojo o en negro, en que se ha sospechado en muchas de ellas la existencia de amputaciones digitales situadas a nivel de las articulaciones interfalángicas (figs. 16 y 17).

En casi todos los yacimientos con improntas hay un franco predominio de la mano izquierda y las presuntas amputaciones casi siempre se limitan a un solo dedo, en general el quinto de la mano izquierda.

Aunque la práctica de las amputaciones digitales es un ritual antropológico bastante frecuente y que parece haberse iniciado hace milenios, nos parece más plausi- 
ble que sea la transcripción de signos mágicos, reflejo de una simbología empleada por los grupos de cazadores para comunicarse entre sí, evitando emitir sonidos que podrían alertar a las presas. Que casi siempre los signos correspondan a la mano izquierda nos parece también lógico, pues seguramente la derecha empuñaba el arma y la izquierda quedaba libre para los signos. Un lenguaje digital de este tipo lo practican en la actualidad algunos grupos de bosquimanos (fig. 18). También los sordomudos emplean un lenguaje digital (fig. 19). Hemos constatado, al igual que experimentalmente hiciese SollAS, que la flexión de algunos dedos producen imágenes susceptibles de confusión con amputaciones (fig. 20). A conclusiones similares a las nuestras había llegado LEROI-GOURHAN en su magnífico estudio de 1967 y posteriormente PIVETEAU (1991).

Un hecho curioso dentro de las veleidades artísticas de los dibujantes de animales de cuentos infantiles, es su tendencia a la reducción de dedos en las extremidades, como, por ejemplo, los cuatro dedos del Mickey Mouse de WALT DISNEY.

Nuestra impresión es de que la mayoría de las presuntas "mutilaciones digitales" corresponden a una transcripción de signos rituales, aunque no se puede excluir por completo, que en algún caso se tratase de una amputación accidental o ritual.

\section{COMENTARIO FINAL}

En cuanto hace referencia a las manos, no son muchos los hallazgos paleopatológicos, casi inexistentes hasta que nos adentramos en el Neolítico, siendo las afecciones reumatoideas, los procesos infecciosos y los traumatismos la patología dominante. Se confirma la presencia de la amputación punitiva de las manos, mientras que las amputaciones digitales rituales, no parece haber sido una práctica habitual en la prehistoria. Por último, debemos destacar que no tenemos constancia de ningún tipo de actuación quirúrgica con base paleopatológica.

\section{AGRADECIMIENTOS}

Agradezco a los fotógrafos del Museu d'Arqueologia de Catalunya, Sres. Oriol Clavell y Julia Martínez y a la Sra. Anna Maria Mestre, colaboradora del Laboratorio, su desinteresada colaboración. 


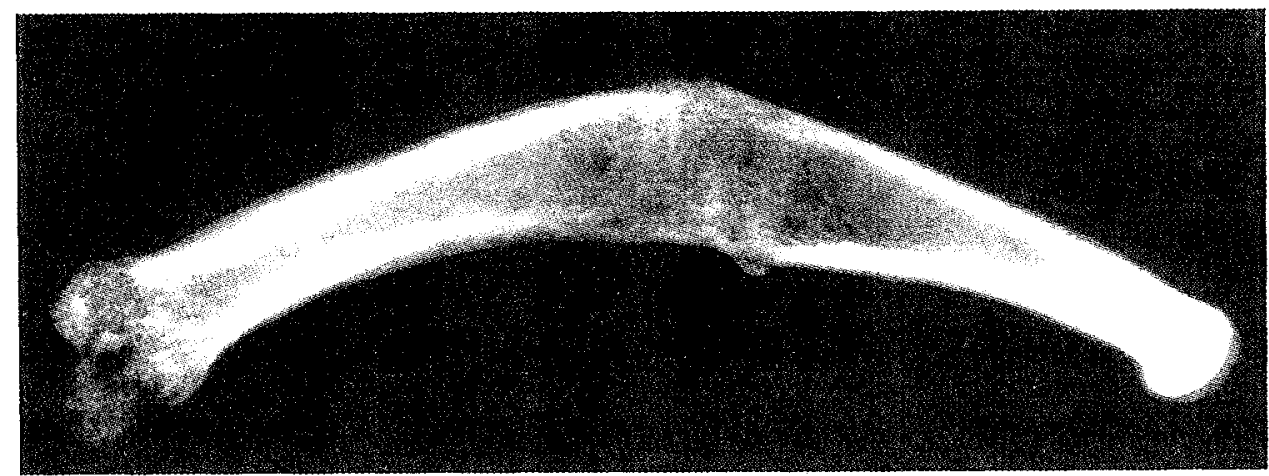

Fig. 1. Radiografia de una anquilosis metacarpofalángica en flexión, en un individuo de S'Illot des Porros (Mallorca) perteneciente a la cultura talayótica (siglos V-IV a.C.). En la fusión ósea, aún se pueden ver restos de las facetas articulares sin exostosis, con cavidades necróticas y alteración de la cortical en las proximidades de la fusión. Estas lesiones resultan sospechosas de ser secundarias, probablemente, de un proceso infeccioso piógeno.

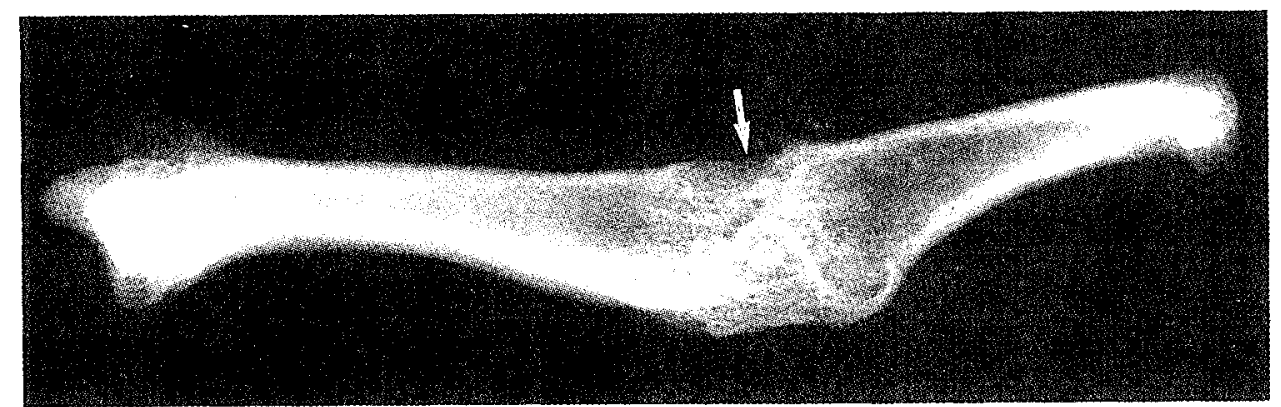

Fig. 2. En otro individuo, también procedente de S'lllot des Porros, la radiografía muestra una anquilosis metacarpofalángica en hiperflexión. Sus características son similares a las de la figura precedente, pero parece existir una antigua fractura (flecha), que nos hace sospechar de que fuese secundaria a una fractura abierta sobreinfectada. 


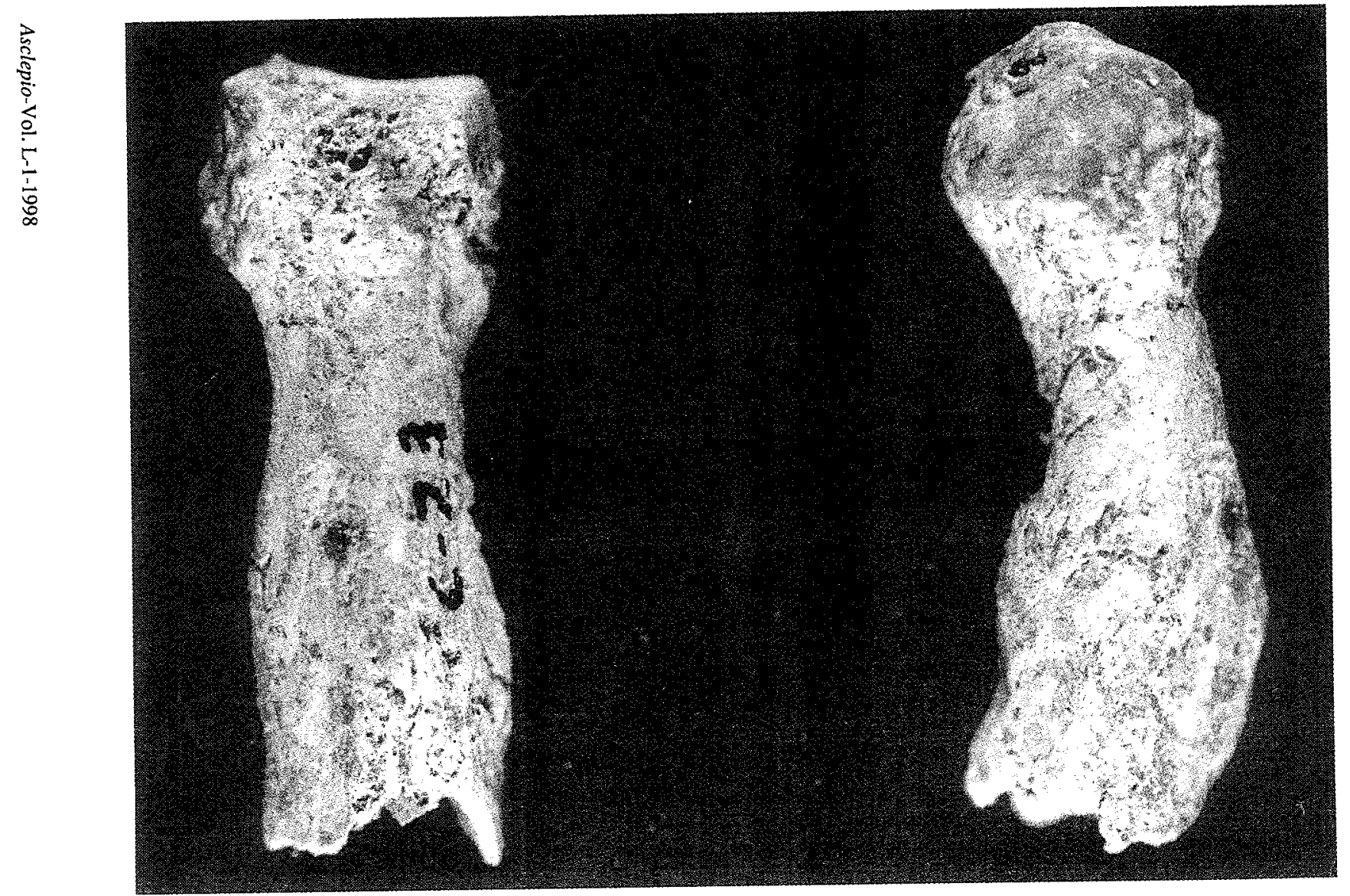

Fig. 3. Falange vista de frente y de perfil, procedente del yacimiento visigótico de Clunia (Burgos). Su epífisis proximal está deteriorada post mortem, pero se puede apreciar el abultamiento de la diáfisis. 
DOMINGO CAMPILLO

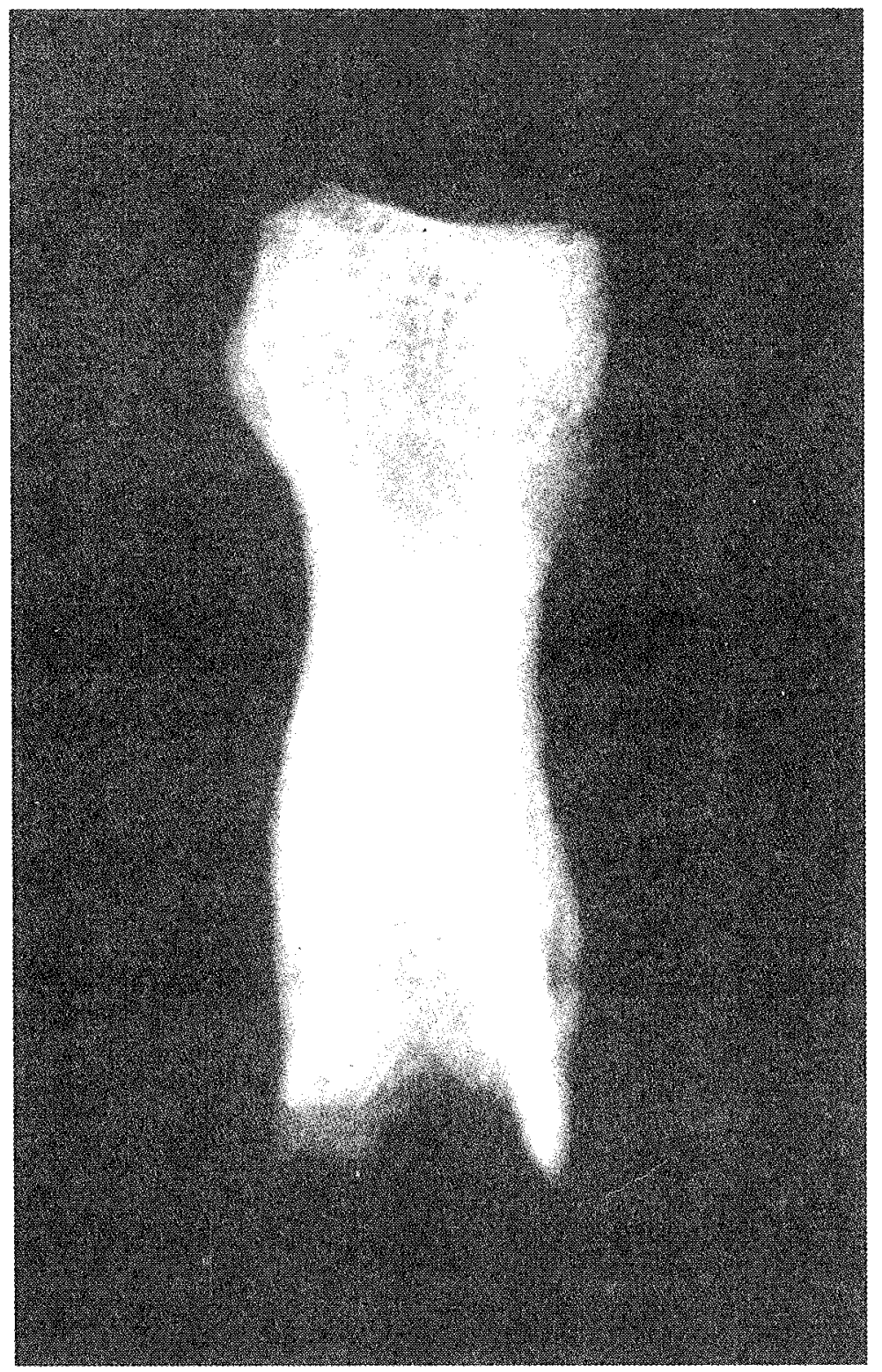

Fig. 4. Radiografia de la falange de la figura precedente, que muestra como un desdoblamiento de la cortical diafisaria le da un aspecto insuflado, que la hace sospechosa de tratarse de que en vida hubiese una espina ventosa. 

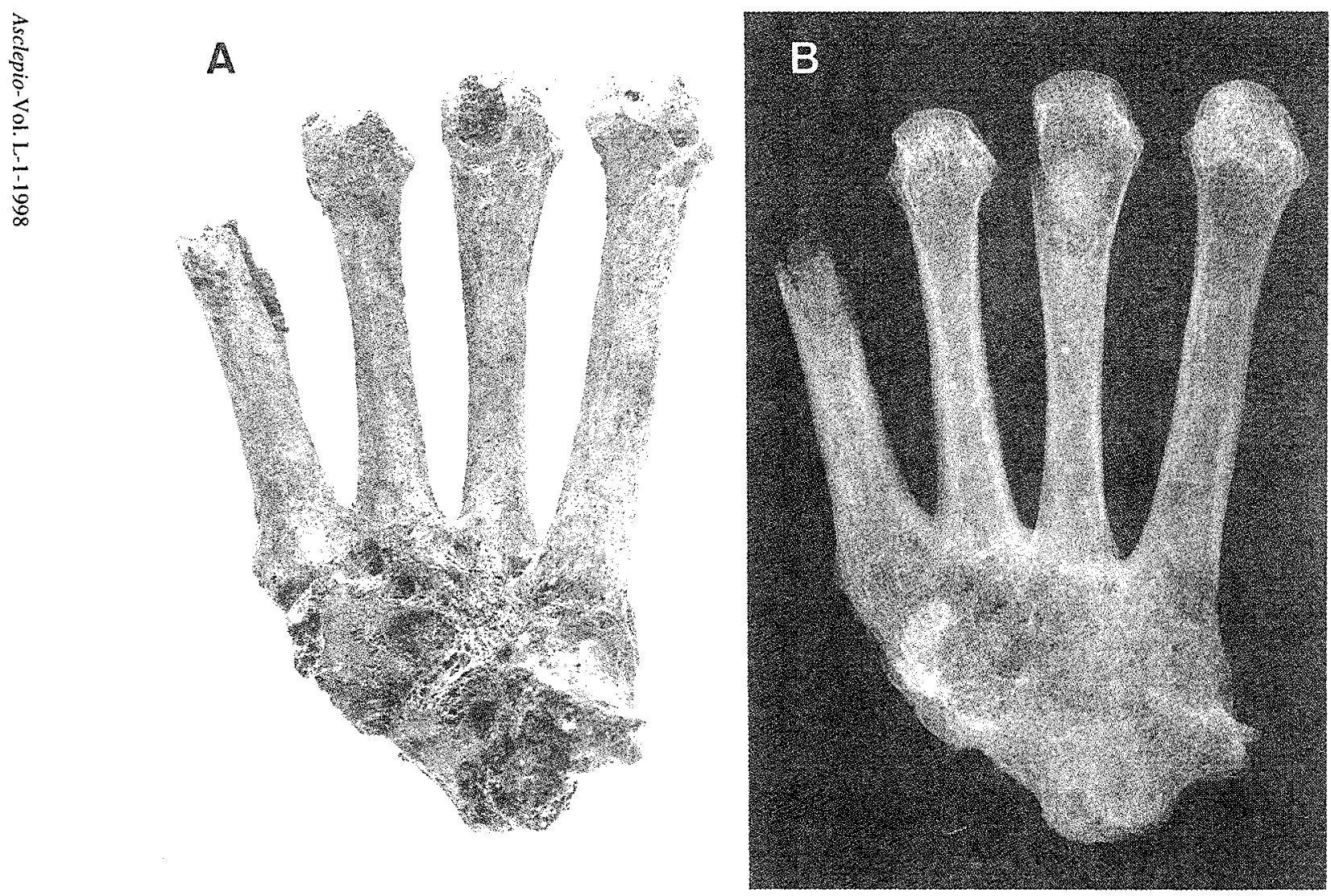

0
2
0
0
0
0
0
0
0
0
5
3
3
0
0

Fig. 5. A) Anquilosis carpometacarpiana de una mano derecha, probablemente femenina, procedente del Codolar de Biniatram (Menorca), que según la fusión ósea que apreciamos en la radiografía (B), resulta sospechosa de corresponder a una artritis reumatoide. 


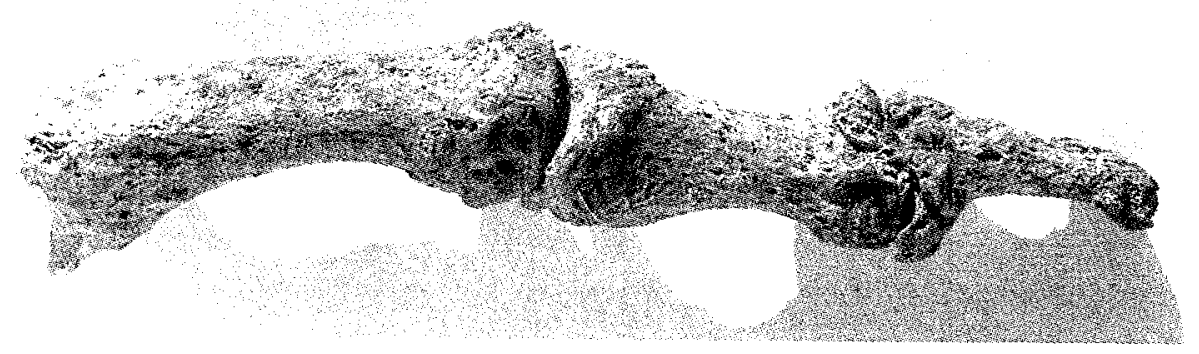

Fig. 6. Procedente del Barranc d'En Llopis (Valencia), perteneciente al período romano, observamos importantes alteraciones óseas artríticas en un dedo, de cuyo individuo, a juzgar por las alteraciones osteoarticulares del resto de su esqueleto, resulta sospechoso de haber padecido en vida un reumatismo hiperuricémico.

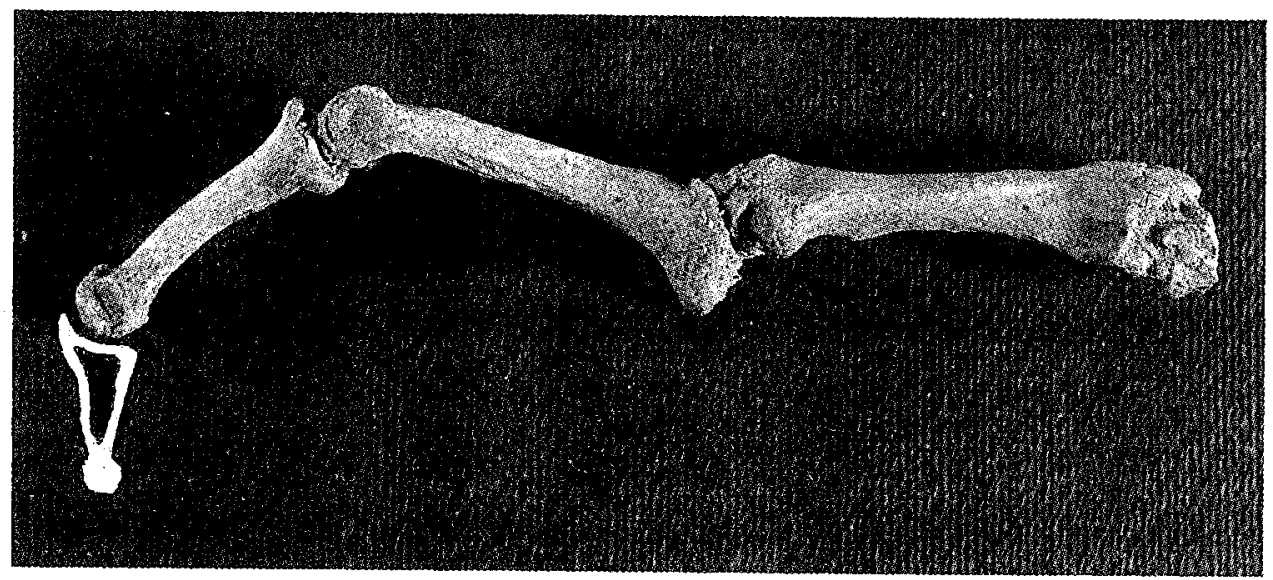

Fig. 7. Esqueleto de un cuarto dedo, que por la modificación de sus facetas articulares corresponde a una típica "garra cubital". El esqueleto que mostraba típicas alteraciones de artritis reumatoide, con anquilosis de ambos codos, que habría dado lugar a un atrapamiento del nervio cubital en la corredera epitrocleo-olecraneana, corresponde al período tardorromano y fue exhumado en el "Parc de la Ciutat" (Tarragona). En blanco hemos dibujado la posición probable de la tercera falange. 


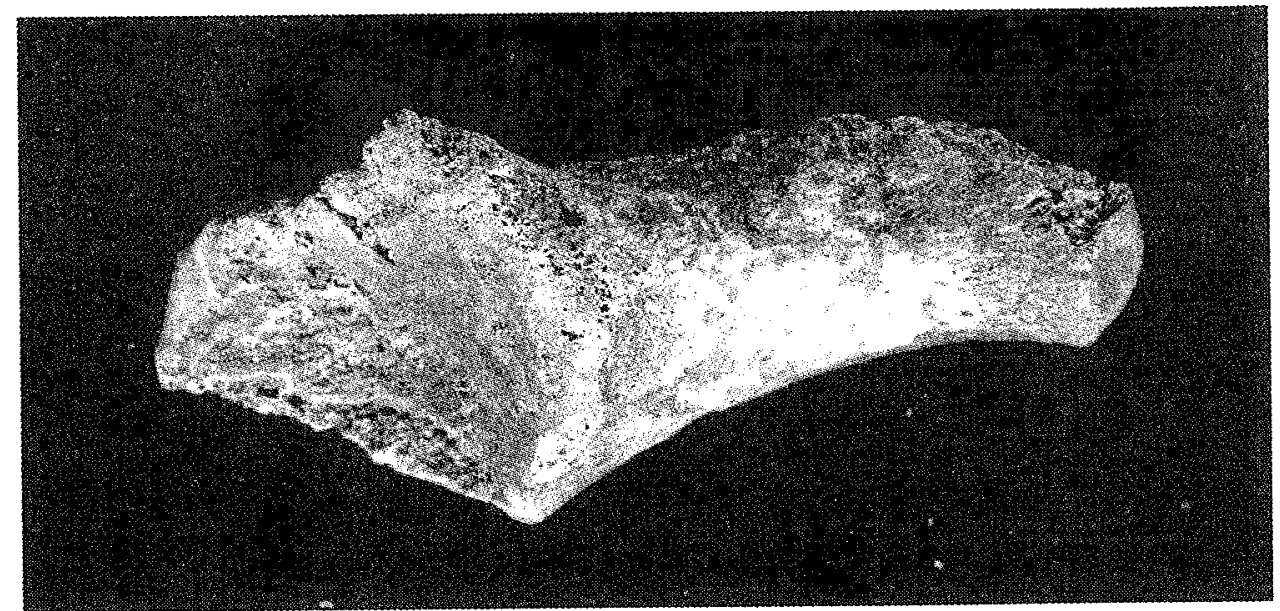

Fig. 8. En un enterramiento de Clarena perteneciente al período neolítico, entre los restos óseos, se exhumó esta segunda falange en que por la modificación de su carilla articular proximal, resulta sospechosa de que hubiese habido una flexión digital en "garra", de etiología incierta.

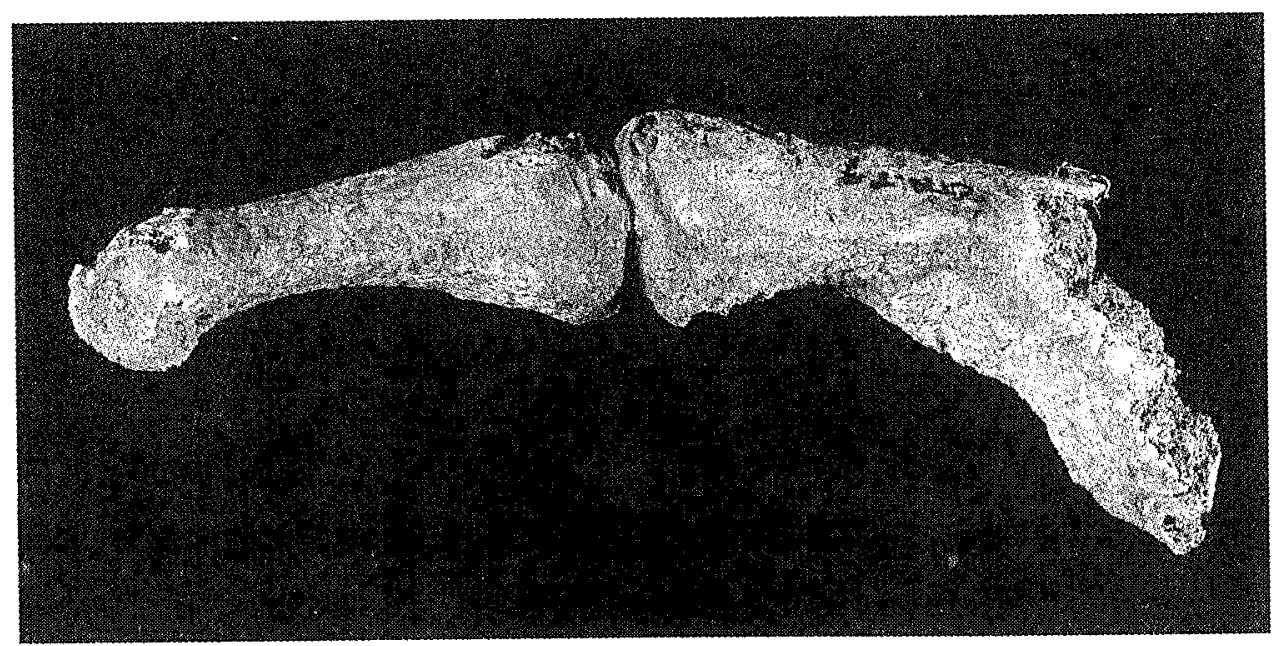

Fig. 9. Fractura con consolidación defectuosa en flexión de un metacarpiano exhumado en la necrópolis romana de Can Trullas (Granollers, Valles Oriental). 


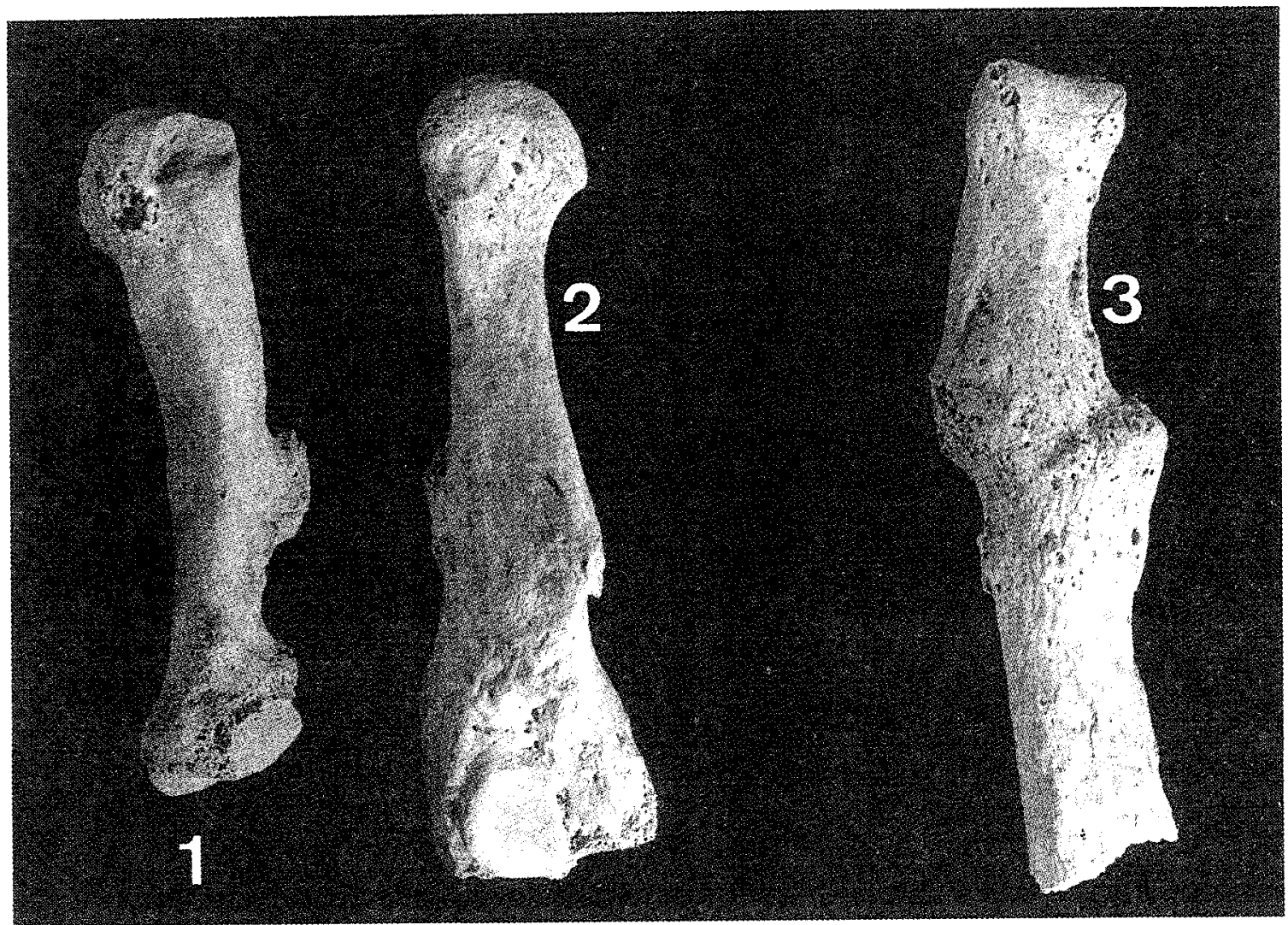

Fig. 10. Metacarpianos y falanges procedentes de distintos individuos exhumados en la necrópolis medieval del siglo X, situada en el subsuelo del crucero del Reial Monestir de Santa Maria de Ripoll. 1) exostosis diafisaria; 2) fractura diafisaria bien consolidada con un grueso callo de fractura; 3) Anquilosis, probablemente postraumática entre una primera y segunda falange. 


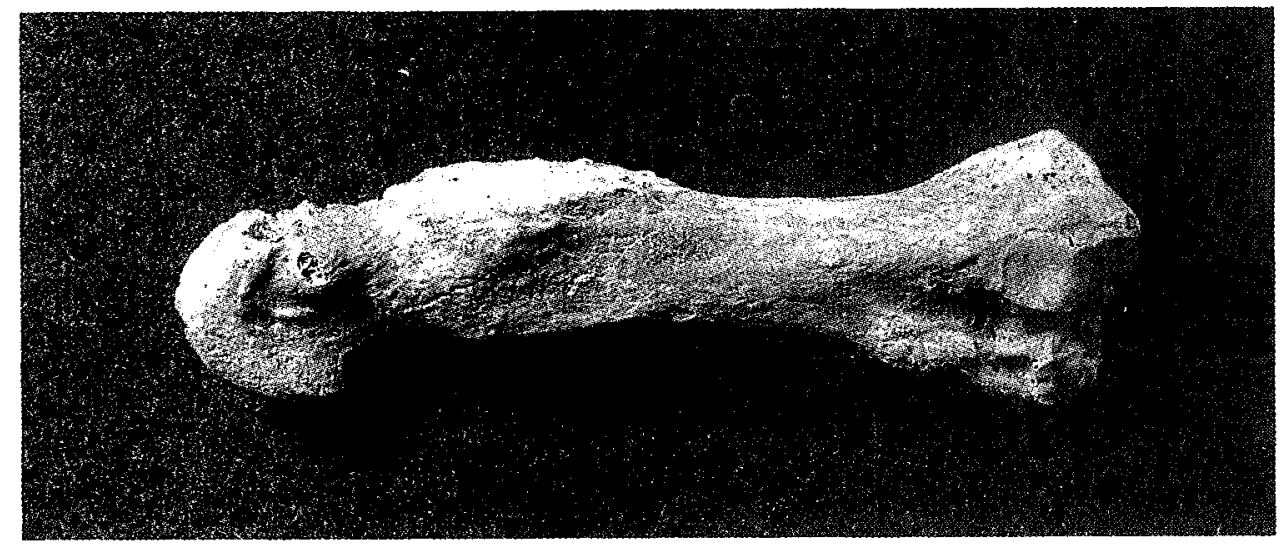

Fig. 11. Fractura con consolidación con torsión de la diáfisis de un metacarpiano metacarpiano, procedente de un individuo de época medieval, exhumado en Sant Vicenc d'Enclar (Principat d'Andorra).
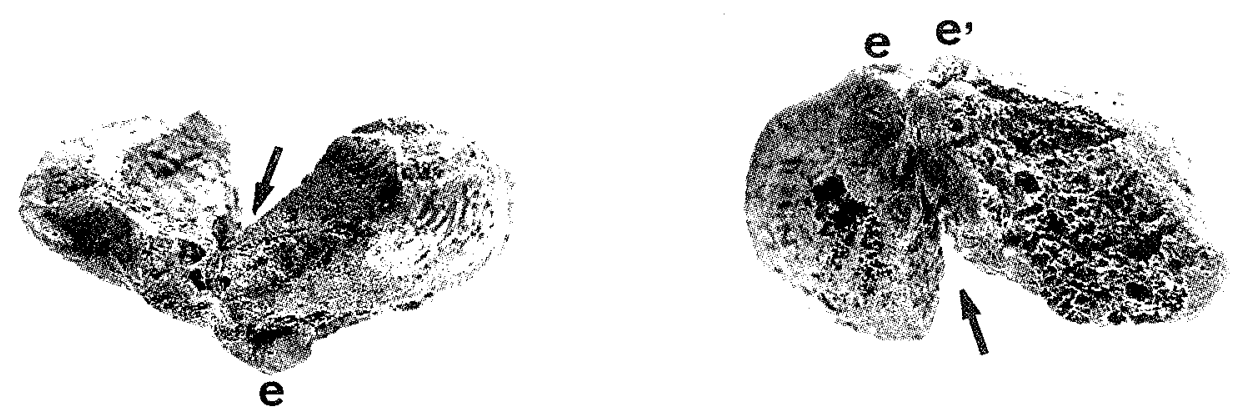

Fig. 12. Fractura de un escafoides de la mano izquierda, con reabsorción postnecrosis isquémica de un sector triangular (flechas), que se conoce como enfermedad de Preisser. En los bordes de la fractura se observan exostosis. Perteneciente a la Edad del Bronce fue exhumado en "La Fonollera" (Torroella de Montgrí, Girona). 
DOMINGO CAMPILLO

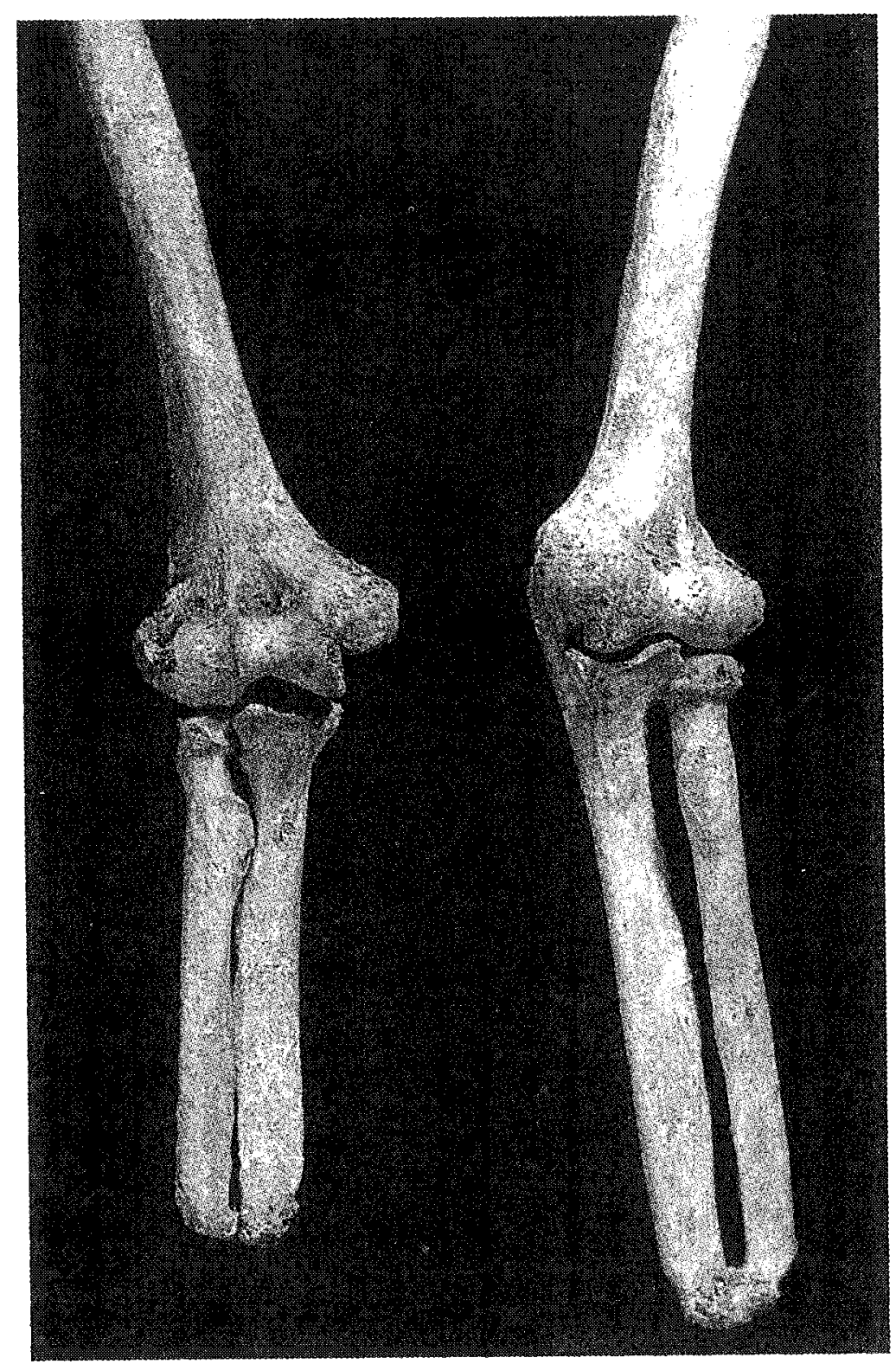

Fig. 13. Amputación de ambas manos, por sección punitiva a nivel de los antebrazos en el individuo núm. 52 de "La Olmeda" (Pedrosa de la Vega, Palencia). (Período paleocristiano). 

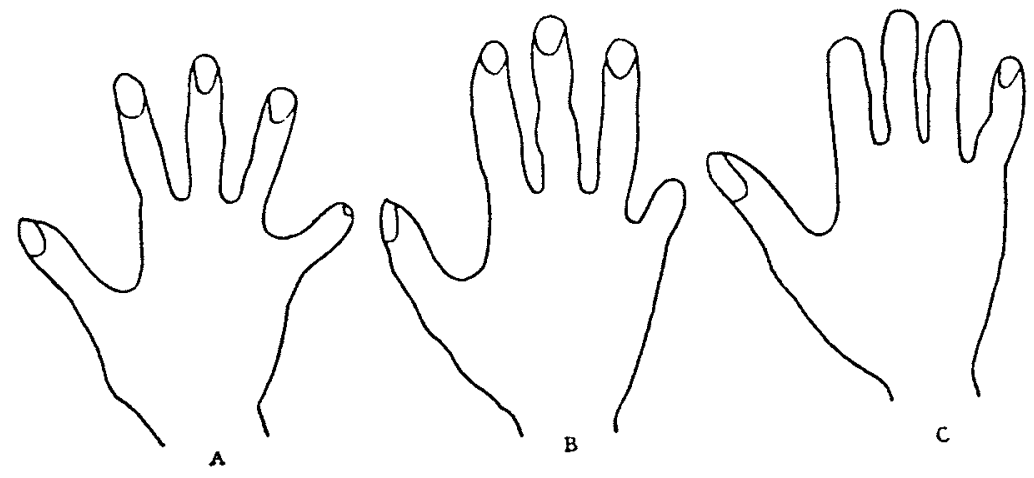

Fig. 14. Esquemas de algunas amputaciones digitales por desarticulación interfalángicas, en las manos de algunos bosquimanos, según VIRCHOW.

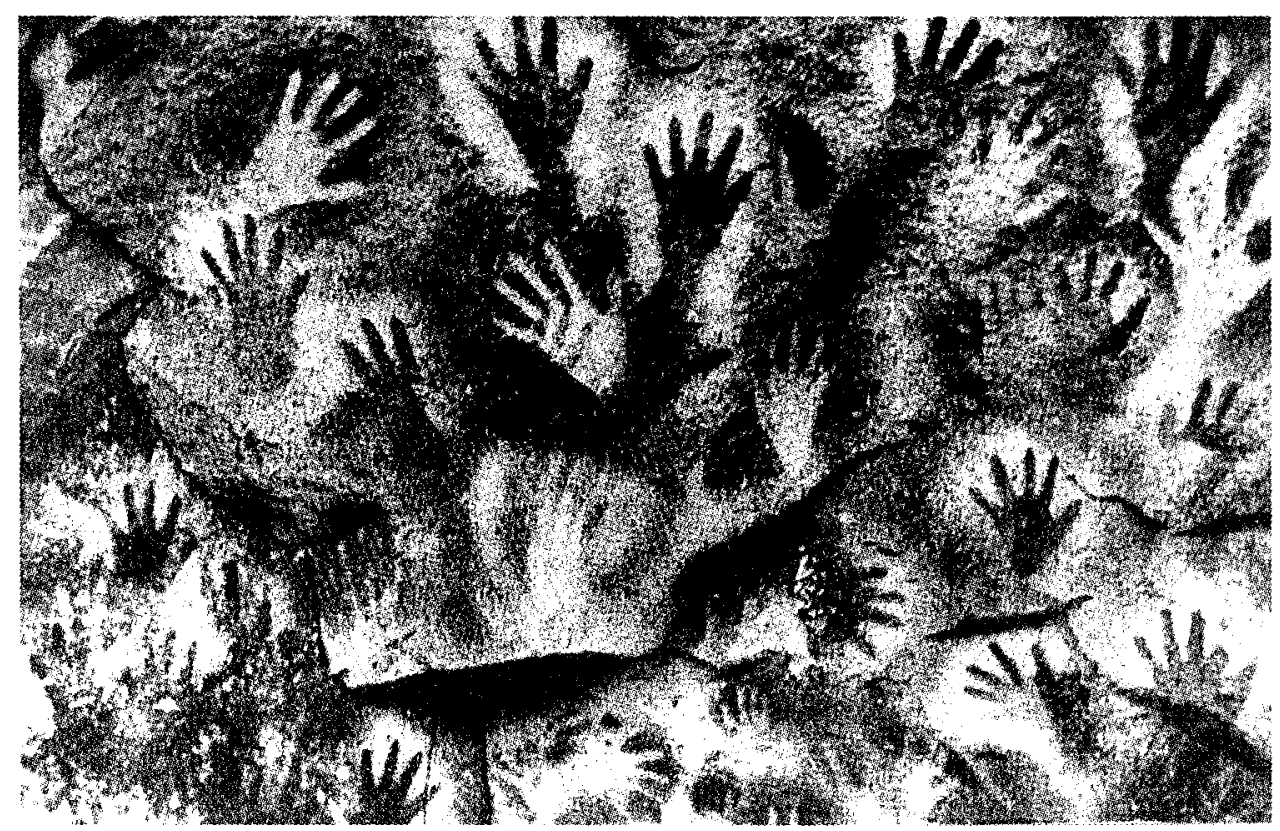

Fig. 15. Improntas negativas de manos en la cueva del Comodoro Rivadavia (República Argentina), según Menghin. 
DOMINGO CAMPILLO

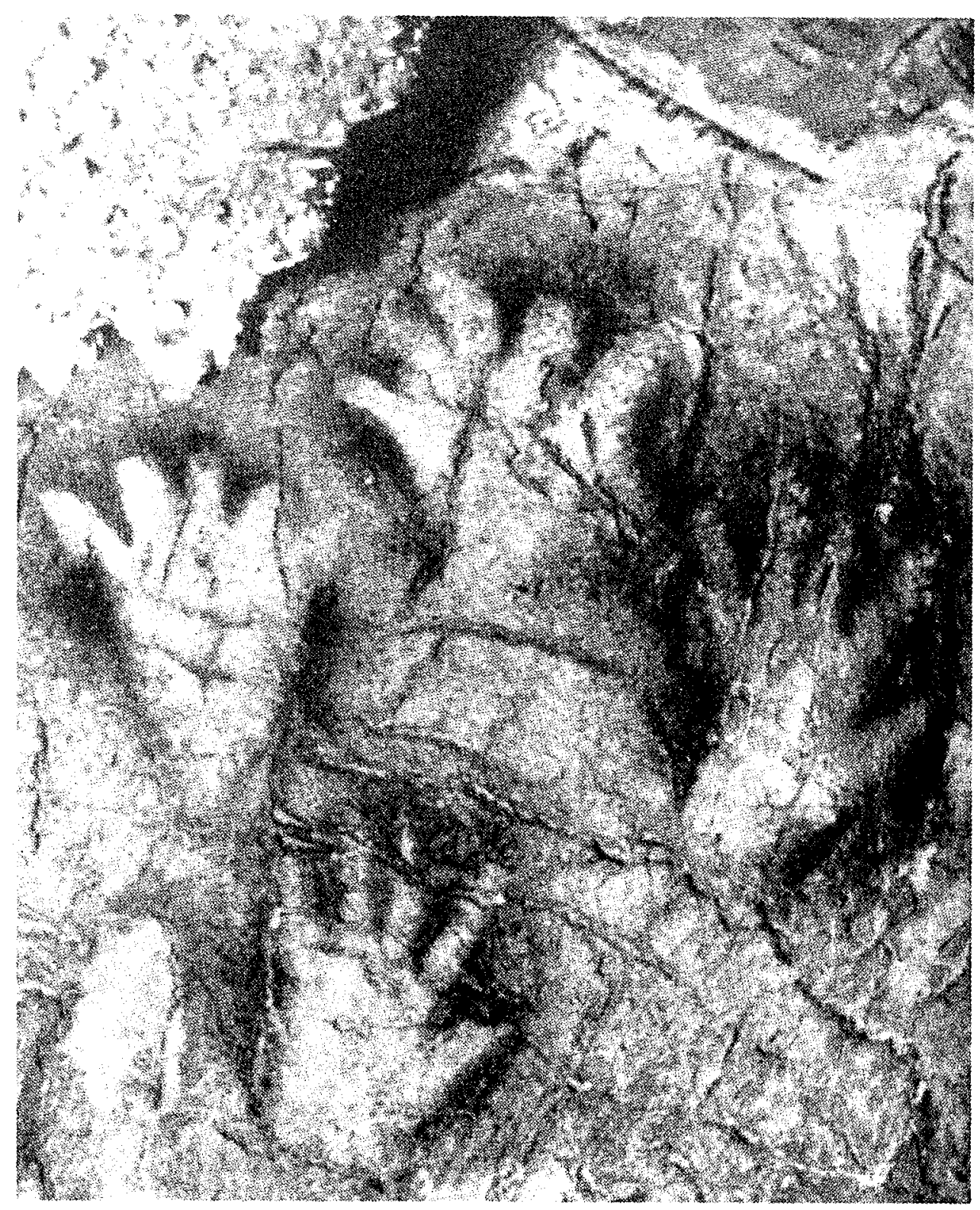

Fig. 16. Improntas de manos procedentes de la cueva de Gargas, sugerentes de amputaciones digitales. 


\section{PALEOPATOLOGÍA DE LA MANO}
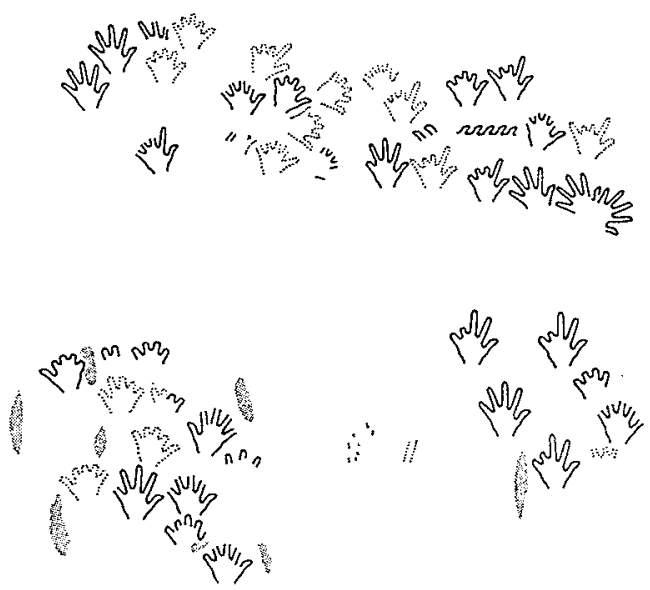

Fig. 17. Esquemas de manos mutiladas procedentes de la cueva de Gargas, (tomadas de LEROIGOURHAN). En trazo continuo impresas en color negro y en trazo discontinuo en color rojo.
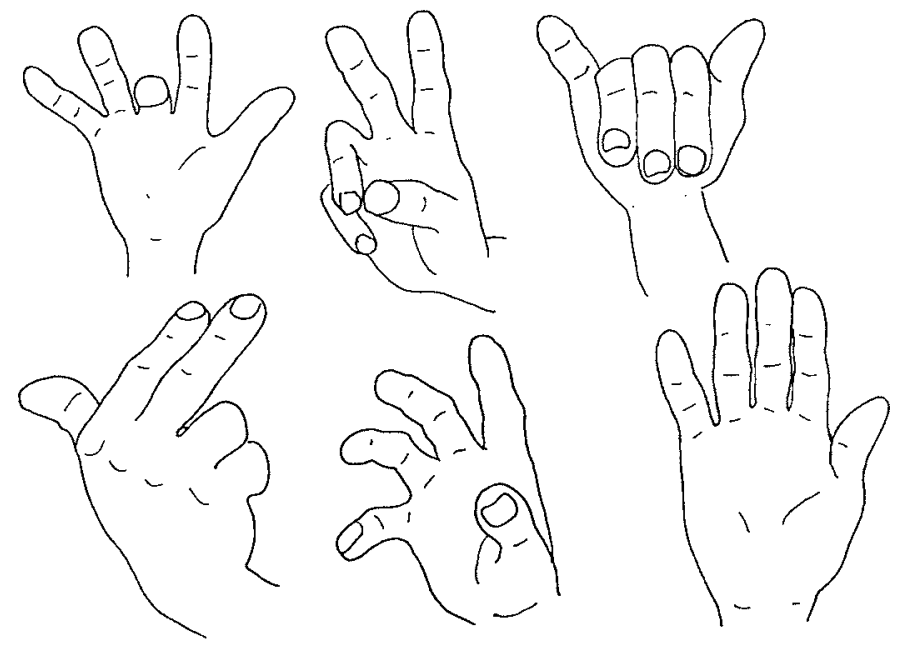

Fig. 18. Algunos signos manuales empleados durante la caza por los bosquimanos, para no emitir sonidos que pudiesen alertar la caza. 
DOMINGO CAMPILLO

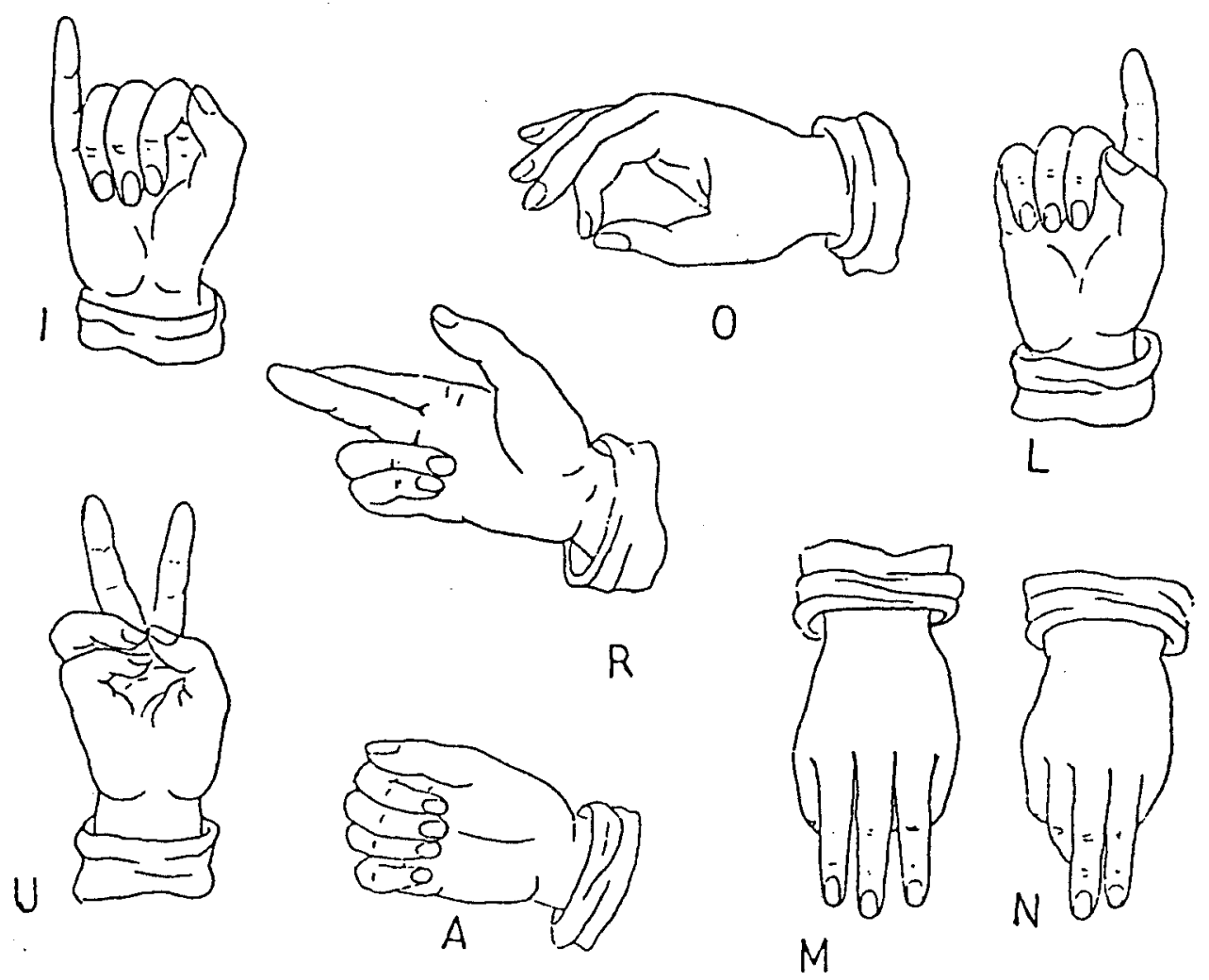

Fig. 19. Posición de los dedos de la mano que significan letras en el lenguaje de los sordomudos. 


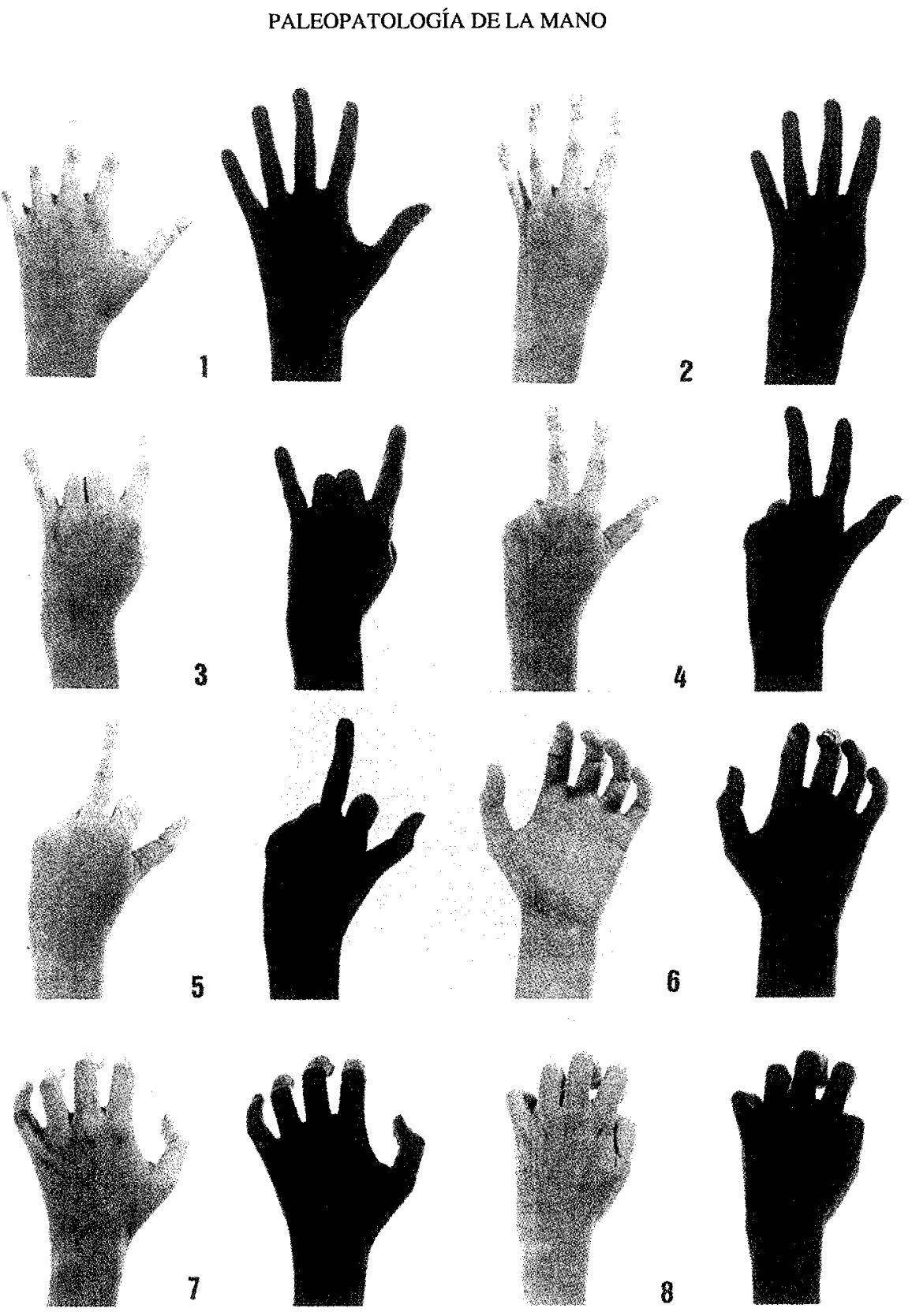

Fig. 20. Trabajo fotográfico experimental, para mostrar como se pueden originar imágenes similares a las amputaciones digitales por desarticulación interfalángica. 
DOMINGO CAMPILLO

\section{BIBLIOGRAFÍA}

APPELbOOM, T. (Ed.), 1987, Art, History and Antiquity of Rheumatic Diseases, Brussels, Erasmus Fundation.

BENNIKE, P., 1985, Paleopathology of Danish Skeleton, Copenhagen, Akademisk Forlag.

BOSCH GIMPERA, P., 1964, "El arte rupestre de América", en Miscelánea en homenaje al Abate Henri Breuil, II., pp. 269-278. Barcelona, Inst. Prehist. y Arqueol.

BreuIL, H., 1952, “Quatre cents siècles d'art parietal”. Monignac, pp. 246-257.

BREUIL, H., 1954-1955, "La décoration pariétale préhistorique de la grotte de Gargas Bull". Soc. Meridionale spéléol. et Préh., 5: 301-409.

Brothwell, D. and SANDison, A. T., 1967, Diseases in Antiquity, Springfield, Ch. C. Thomas.

CAMPILlo, D., 1983, La enfermedad en la prehistoria, Barcelona, Salvat.

CAmpillo, D.; Hernández, M.; Chimenos, E., y Turbon, D., 1992, "Étude anthropologique et paléopathologique du squelette médiéval 0-52 de "La Olmeda" (Pedrosa de la Vega, Province Palencia, Espagne)". Paleobios, 8 (1-2): 23-32.

CAMPILlo, D., 1984-1985, Documentos históricos de patología osteoarticular, (colección de 19 trípticos), Barcelona, Ed. Fher.

CAMPILlo, D., 1986-1989 "Osteo-articular tuberculosis in the Middle Ages in Spain", Empúries, 48-50: 142-151.

Campillo, D., 1993-1994, Paleopatología. Los primeros vestigios de la enfermedad, BarceIona, Fundació Uriach-1838.

CARTAILHAC, E., 1906, "Les mains inscrites de rouge ou noir de Gargas", L'Anthropologie, 17: 624-625.

CoHEN, A., "A Study of Rheumatic Disorders in Far Eastern (largely Japanese) Art", en Appelboom, p. 23.

Dastugue, J., 1992, Paleopathologie du squelette humain, Paris, Boubée.

DUDAY, H., 1975, Le esquelette du sujet feminin de la sepulture preneolithique de Bonifacio (Corse), Paris, C.N.R.S.

ESPASA (Ed.), 1930, Enciclopedia universal ilustrada europeo-américana, Vol. 37, Barcelona, Espasa, pp. 776-781.

ETXEBERRIA, F., 1983, Estudio de la patología ósea en poblaciones de época Alto Medieval en el País Vasco, San Sebastian, Eusko-ikaskuntza.

Gorlin, R. J.; Pindborg, J. J., y Cohen, Jr. M. M., 1979, Síndromes de la cabeza y cuello, Barcelona, Toray.

GRMEK, M., "Deformities of the Spine and Rheumatic Diseases in Greco-Roman Art", en Appelbbom, pp. 17. 


\section{PALEOPATOLOGÍA DE LA MANO}

HOWELl, F. C., 1971, El hombre prehistórico, Barcelona, Salvat.

LECA, P., 1971, La médicine égyptienne au temps des pharaons, Paris, Roger Dacosta.

Leroi-Gourhan, A., 1967, "Las mains de Gargas. Essai pour une étude d'ensemble", Bull. Soc. Préh. fr., LXIV: 107-122.

MACKE, A., y MACKE-RIBET, C., 1994, "Paléodémographie et paléopathologie d'une population égyptienne inhumée dans la nécropole de la Vallée des Reines (Thebes-Ouest, Haute-Egypte)", Anthrop. et Préhist., 105: 5-28.

MAfart, B.-Y., 1983, Paleopathologie osseuse au Moyen Age en Provence, Paris, C.N.R.S.

MAYS, S. A., 1996, "Healed Limb Amputations in Human Osteoarchaeology and their Causes: A Case Study from Psswich, UK”, Intern. J. of Osteoarchaeology, 6: 101-113.

Malgosa, A., y CAMPILlo, D., 1991, "Visión general de las patologías halladas en los individuos de la necrópolis talayótica de "S'Illot des Porros" (Mallorca)", Actas IX Cong. Nacional Hist. Med., Sept. 1989, Zaragoza, Ayuntamiento de Zaragoza.

MENGHIN, citado por P. Bosch Gimpera.

Moller-Christensen, V., "Evidence of Leprosy in Erlier Peoples" (en Brothwell, D. and Sandison, A. T., 1967, Diseases in Antiquity, Springfield, Ch. Thomas), pp. 297.

Molleson, T., "The Role of Environment in the Acquisition of Rheumatic Diseases", en Appelboom, pp. 100.

Moodie, R., 1923, "Paleopathology". New York, Ams Press.

ORTNER, J., "Archaeological Evidence of Polyarticular Inflamatory Arthritides in North America”, en Appelboom, pp. 92.

ORTNer, J., y PUTCHAR, W., 1985, "Identification of Pathological Conditions In Human Skeletal Remains", Washington, Smithsonian Inst. Press.

Piveteau, J., 1957, Traité de Paléontologie, VI, Paris, Masson.

Piveteau, J., 1991, La main et l'hominisation, Paris, Masson.

Simon, L.; Blotman, F., y Claustre, J., 1976, Manual de Reumatología, Barcelona, TorayMasson.

Sollas, W. J., 1924, Ancient Huntersn, London, Macmillan Co. 20.

STEINBOCK, T., 1973, Paleopathological diagnosis and interpretation, Springfiel, Ch. C Thomas.

VAllois, H., 1949, Paléopathologie et paléontologie humaine, Homenaje a Don Luis de Hoyos Sainz, 1: 333-341.

WELLS, C., 1964, Bones, Bodies and Disease, London, Thames and Hudson. 